\title{
Effect of Growth Temperature on Aster Flower Development
}

\author{
M. Oren-Shamir ${ }^{1}$, L. Shaked-Sachray ${ }^{2}$, and A. Nissim-Levi ${ }^{3}$ \\ Department of Ornamental Horticulture, Agricultural Research Organization, \\ The Volcani Center, P.O. Box 6, Bet Dagan 50250, Israel
}

D. Weiss ${ }^{4}$

Department of Horticulture, Faculty of Agriculture, The Hebrew University of Jerusalem, P.O. Box 12, Rehovot 76100, Israel

Additional index words. Aster sp., flower induction, flower longevity, flower morphology, shading

\begin{abstract}
Little is known about the effect of growth temperature on Aster (Compositae, Asteraceae) flower development. In this study, we report on this effect for two aster lines, 'Suntana' and 'Sungal'. Growth temperature had a dramatic effect on the duration of flower development, ranging from 22 days for plants growing at $29^{\circ} \mathrm{C}$ up to 32 days for plants grown at $17^{\circ} \mathrm{C}$. Flower longevity was $\approx 40 \%$ shorter under the higher temperature for both lines. Growth temperature also affected flowerhead form: 'Suntana' flowerhead diameter was $20 \%$ larger at $17{ }^{\circ} \mathrm{C}$ than at $29{ }^{\circ} \mathrm{C}$. The number of 'Sungal' florets per flowerhead was four times greater at the lower temperature. Shading $(30 \%)$ under temperature-controlled conditions had no effect on any of the parameters measured. For plants grown outdoors, our results suggest that shading plants may increase quality by reducing the growth temperature.
\end{abstract}

Aster is a flowering perennial in the Compositae family. The center of the flowerhead (capitulum) consists of yellow disk florets, sometimes changing to purple or rosepurple. In most cultivars, the center of the flowerhead is surrounded by one or two rows of petal-like ray florets that are blue, purple, violet, pink, or white. Induction of flowering in aster is in two stages: first a period of long days (at least $16 \mathrm{~h}$ of light) is required for the induction of stem elongation, and then a period of short days (10 h of light or less) for flower initiation (Schwabe, 1985). About 500 aster species are native to the Americas, and others are native to Europe, Asia, and South Africa. The name, alluding to the form of the flowerheads, is from the Latin aster, a star. Asters are grown as garden flowers as well as for the cut-flower market.

Although not studied in asters, the effects of growth temperature on flower size and shape has been studied in several other flowers. Blueberry (Vaccinium sp.) flower size is not affected significantly by growth temperature (Lyrene, 1994). In contrast, chrysanthe-

Received for publication 18 June 1998. Accepted for publication 12 Apr. 1999. We thank Dan flower farm for supplying the plants for this study, and Itzhak Forer for his technical help and maintenance of the phytotron experiments. This research was supported by the Chief Scientist of the Israeli Agriculture Ministry (Grant No. 256-0438-96). The cost of publishing this paper was defrayed in part by the payment of page charges. Under postal regulations, this paper therefore must be hereby marked advertisement solely to indicate this fact.

${ }^{1}$ Associate Professor; to whom reprint requests should be addressed.

${ }^{2}$ Graduate Research Assistant.

${ }^{3}$ Research Associate.

${ }^{4}$ Associate Professor. mum (Dendranthema $\times$ grandiflora Kitam.) flower size decreases as temperature increases (Ben Hod et al., 1989; Sharman et al., 1989). Several studies have identified the specific stage of development in which the flower is sensitive to temperature. Exposure of pansy (Viola $\times$ wittrockiana Gams.) shoots to different temperature regimes, prior to visible bud formation, has little if any influence on final flower size, while exposure of visible buds has a clear effect (Pearson et al., 1995). The influence of temperature on flower size was maximal when plants were transferred to lower temperature coincidentally with visible bud formation, yielding significantly larger flowers. When transferred at later stages of bud development, plants produced intermediatesize flowers. Conversely, reducing the temperature before bud appearance reduced the number of petals in carnation (Dianthus caryophyllus L.) (Garrod and Harris, 1974). Little is known about the effect of temperature on the size of the aster flowerhead and on the length of flowering time, although growers have noted that flowerhead size typically is smaller during the summer than in cooler weather.

In this study we focused on two commercially available cut-flower aster lines, 'Suntana' and 'Sungal', developed by Dan flower farm in Israel. The plants from both lines are very similar in appearance, and both have a yellow flowerhead center. The 'Suntana' rays are purple-pink while 'Sungal' rays are purpleblue. 'Suntana's color is relatively stable at high temperatures, unlike the 'Sungal' flowers, which fade when grown at high temperatures (Orna Shoham, Dan flower farm, personal communication). The 'Sungal' line grows faster and gives higher yield and therefore is more successful in the cut-flower market. Ge- netic information on the relation of the two lines is not available. Here we report on a study of the effect of growth temperature on aster flowering and on the development of flowerheads. These characterizations may be of value to aster growers, since they indicate how to manipulate temperature to improve flower quality.

\section{Materials and Methods}

Plant material. Two seedling aster lines, 'Suntana' and 'Sungal' (both hybrids of the species ericoides and pilosus), developed for the cut-flower market by Dan flower farm (Mishmar Hashiva, Israel), were used.

Growth conditions. Young seedlings were planted in pots and transferred to $23^{\circ} \mathrm{C}$ day $/ 15$ ${ }^{\circ} \mathrm{C}$ night growth temperatures in a humidityand temperature-controlled glass greenhouse, with ambient $\mathrm{CO}_{2}$ and $65 \%$ humidity, where they remained throughout the experiment. The accuracy of temperature control in all the greenhouse rooms was $0.5^{\circ} \mathrm{C}$, and the change from day to night temperature occurred gradually during a period of $2 \mathrm{~h}$.

Short-day (SD) regimes were achieved in the greenhouse by covering the glass walls with black curtains after $10 \mathrm{~h}$ of sunlight. Sunlight photosynthetic photon flux $(P P F)$ $(400-700 \mathrm{~nm})$ varied between 300 and 800 $\mu \mathrm{mol} \cdot \mathrm{m}^{-2} \cdot \mathrm{s}^{-1}$ depending on the weather, but was identical in all rooms. Long-day (LD) regimes were attained by extending the photoperiod by 10 hours (1700-0300 HR) using incandescent lamps $\left(2 \mu \mathrm{mol} \cdot \mathrm{m}^{-2} \cdot \mathrm{s}^{-1} P P F\right)$.

Seedlings were grown for 4 weeks under LD conditions until plants reached an average height of $40 \mathrm{~cm}$. To ensure prevention of bud formation in all plants at this stage, 10 additional hours of photoperiodic light were given. Plants were then transferred to SD conditions in order to induce flowering. After flower bud initiation was detected, 10 plants of each line were transferred to rooms maintained at $17^{\circ} \mathrm{C} /$ $9^{\circ} \mathrm{C}, 23{ }^{\circ} \mathrm{C} / 15^{\circ} \mathrm{C}$, and $29^{\circ} \mathrm{C} / 21^{\circ} \mathrm{C}$ (day/night, respectively), all under SD conditions.

Measurement of flowering period. Fifteen flower buds, randomly selected from the 10 different plants in each line and temperature regime, were marked, and the dates of the floret unfurling and the beginning of aging were noted for each bud. The duration of flower development was defined as the period from bud formation (detected as a slight swelling at the tips of the stems) until the date of floret unfurling. Flower longevity was recorded as the time from floret unfurling until the floret senesced.

Shading conditions. After transfer to the different temperature regimes, eight plants of each line in each room in the greenhouse were covered with $30 \%$ shading net (Polysack Plastic Industries, Nir-Yitzhak, Israel). The shading did not alter the light spectrum reaching the plants but only reduced its intensity.

\section{Results and Discussion}

Duration of growth development. Growth temperature had a dramatic effect on the dura- 
tion of flower development in both lines: At 29 ${ }^{\circ} \mathrm{C}$, the average duration was $22 \mathrm{~d}$ and at $17^{\circ} \mathrm{C}$, floret unfurling occurred only after an average of $32 \mathrm{~d}$ (Fig. 1A). Flowerhead longevity was significantly shorter under higher temperature for both lines (Fig. 1B), especially in 'Suntana'.

Flowerhead size and number of florets. Growth temperature also affected flowerhead size and the number of florets in each flowerhead (Fig. $1 \mathrm{C}$ and D). 'Suntana' flowerhead diameter was $\approx 20 \%$ larger at $17^{\circ} \mathrm{C}$ than at 29 ${ }^{\circ} \mathrm{C}$. The number of 'Sungal' florets per flowerhead was four times as great at the lowest than at the highest temperature, forming several layers of florets per flowerhead. Although temperature had a greater effect on flowerhead size than on the number of florets in 'Suntana', the opposite phenomena were observed in 'Sungal', with a minor effect on flowerhead size, and a very large effect on the number of florets. In all four parameters, in both aster lines, the differences were greater between 17 and $23{ }^{\circ} \mathrm{C}$ than between 23 and $29{ }^{\circ} \mathrm{C}$. This resulted in a significant interaction in all four parameters (Table 1).

Effect of shading. Shading had no significant effect on the four parameters measured (duration of flower development, lifetime of flowerheads, their diameter and the number of florets) (data not shown). Note that shading was carried out under controlled temperature conditions (in a phytotron), and therefore did not affect temperature. However, shading outdoor plants after bud initiation may lower their growth temperature up to $4{ }^{\circ} \mathrm{C}$ (depending on the environmental conditions) and thereby may improve flower quality and increase longevity.

Conclusions. In conclusion, temperature had a dramatic effect on the two aster lines, both on the duration of flower development and on flowerhead longevity. Both were reduced at higher temperature. We have studied the effect of temperature only from the stage in which bud formation was first detected. Clearly, this stage was early enough to show a significant temperature effect in asters.

Temperature had strikingly different effects on the two lines, even though they are phenotypically very similar when grown at mild temperatures. However, in both lines the weight of the flowerheads was significantly greater at the lower temperature, because of either greater diameter ('Suntana') or greater number of florets ('Sungal'). Both phenomena are probably due to the increased duration of flower development at lower temperature, and both increase the market value of the flowers.

\section{Literature Cited}

Ben-Hod, G., J. Kigel, and B. Steinitz. 1989. Photothermal effects on corn and flower development in Anemone cornaria L. Scientia Hort. 40:247258.

Garrod, J.F. and G.P. Harris. 1974. Studies on the glasshouse carnation: Effects of temperature and growth substances on petal number. Ann. Bot. 38:1025-1031.

Lyrene, P.M. 1994. Environmental effects on blueberry flower size and shape are minor. J. Amer. Soc. Hort. Sci. 199:1043-1045.

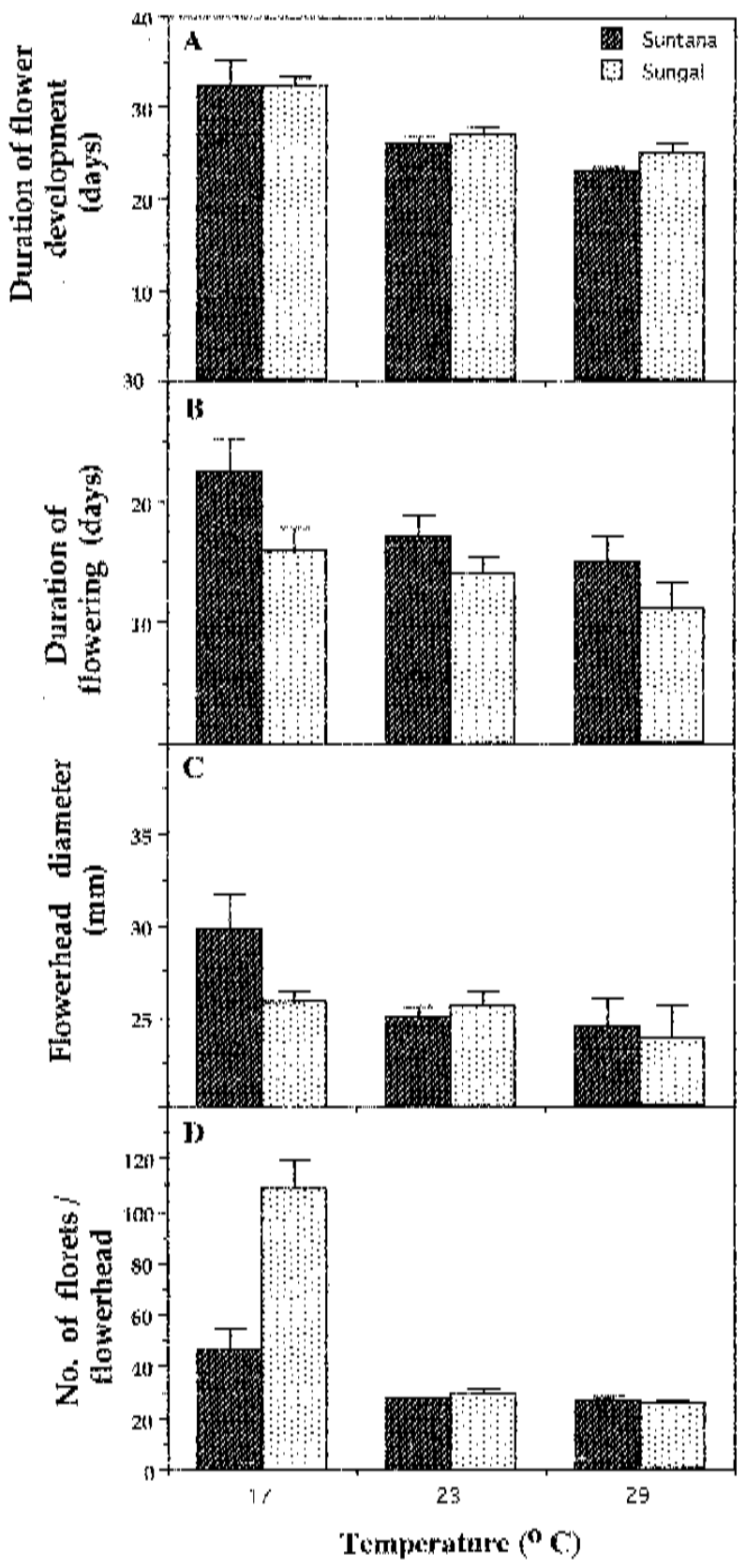

Fig. 1. Temperature effects on the duration of (A) aster flower development, and on (B) flowering, (C) flowerhead diameter, and (D) number of ray florets of 'Suntana' and 'Sungal' flowerheads. The vertical lines represent standard errors of 15 replicates for $(\mathbf{A}),(\mathbf{B})$, and $(\mathbf{C})$, and 10 replicates for $(\mathbf{D})$.

Table 1. Significance of $F$ values for the effects of cultivar, temperature, and their interaction on aster flower longevity, diameter, number of florets/flowerhead, and duration of flower development, following ANOVA. A square root transformation was applied to the number of floret flowerheads prior to analysis to stabilize the variances.

\begin{tabular}{lcccc}
\hline \hline Source & $\begin{array}{c}\text { Duration of } \\
\text { flowering }(\mathrm{d})\end{array}$ & $\begin{array}{c}\text { Flowerhead } \\
\text { diam }(\mathrm{mm})\end{array}$ & $\begin{array}{c}\text { No. of florets/ } \\
\text { flowerhead }\end{array}$ & $\begin{array}{c}\text { Time required for } \\
\text { flower development }\end{array}$ \\
\hline Cultivar $(\mathrm{C})$ & 0.0001 & 0.0133 & 0.001 & 0.0003 \\
Temperature $(\mathrm{T})$ & 0.0001 & 0.0001 & 0.0001 & 0.0001 \\
$\mathrm{C} \times \mathrm{T}$ & 0.0001 & 0.0027 & 0.0001 & 0.0070 \\
\hline
\end{tabular}

Pearson, S., S.R.A. Parker, S.R. Adams, P. Hadley and D.R. May. 1995. The effects of temperature on the flower size of pansy (Viola $\times$ wittrockiana Gams.). J. Hort. Sci. 70:183-190.

Schwabe, W.W. 1985. Aster novi-belgi, p. 29-41. In: Handbook of flowering, vol. 5. A.H. Halevy (ed.). CRC Press, Boca Raton, Fla.
Sharman, K.V., M. Sedgley, and D. Aspinall. 1989. Effect of photoperiod, temperature and plant age on floral initiation and inflorescence quality in the Australian native daisies Helipterum roseum and Helichrysum bracteatum in relation to cut-flower production. J. Hort. Sci. 35:161175 . 